\title{
Internal Carotid Artery
}

National Cancer Institute

\section{Source}

National Cancer Institute. Internal Carotid Artery. NCI Thesaurus. Code C32836.

An artery arising from the bifurcation of the common carotid artery on each side of the body at the level of the third or fourth cervical vertebrae that ascends the neck into the head with numerous branches supplying the anterior brain, eye, forehead and nose. 